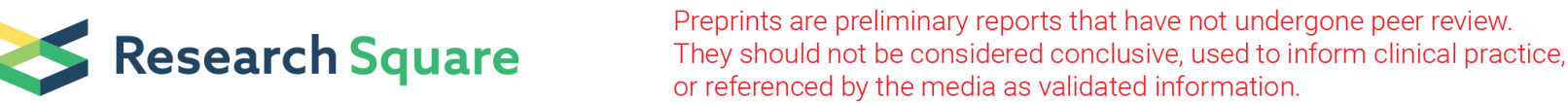

\section{C2-C3 Anterior Cervical Discectomy and Fusion (ACDF) for Hangman's Fractures with C2 Posterior Dislocation: A Modified Classification of Hangman's Fractures and Technical Notes}

\section{Yufei Chen}

Air Force Medical Center of PLA

Guannan Luan

Chinese Academy of Medical Sciences \& Peking Union Medical College

Xiaojie Li

Air Force General Hospital PLA

Hongxing Zhang

Air Force General Hospital PLA

Jingyuan Li

Air Force General Hospital PLA

Ye Peng

Air Force General Hospital PLA

Shuang Ma

sanmenxia yellow river hospital

Songlin Li

Air Force General Hospital PLA

Jing Xue

Air Force General Hospital PLA

Junjie Du ( $\nabla$ dujunjie205@hotmail.com )

Air Force Medical Center of PLA

\section{Technical note}

Keywords: anterior cervical discectomy and fusion (ACDF), hangman's fracture, posterior dislocation, classification, technical note

Posted Date: August 30th, 2021

DOI: https://doi.org/10.21203/rs.3.rs-838380/v1 
License: (c) (i) This work is licensed under a Creative Commons Attribution 4.0 International License. Read Full License 


\section{Abstract}

Background: The overwhelming majority of hangman's fractures cause anterior dislocation of C2. Hangman's fracture with C2 posterior dislocation is extremely rare, only one paediatric case was reported in 2018 to date. This kind of injury cannot be catalogued using current classification schemes and no established treatment recommendations exist. The purpose of this article is to report a rare case of a hangman's fracture with $\mathrm{C} 2$ posterior dislocation, which does not fit into existing classification systems, propose a new subtype of hangman's fractures, and discuss management technical notes for the new subtype to avoid pitfalls.

Methods: Description of case, review of relevant literatures and share our experience.

Results: A 31-year-old male sustained hangman's fracture with C2 posterior dislocation after fell into a $50 \mathrm{~cm}$ deep roadside ditch when riding a motorcycle. Radiograph and computed tomography (CT) on admission showed fractures through both pars of C2 and C2 posterior dislocation. Magnetic resonance imaging (MRI) on admission showed high T2-weighted signal intensity of cervical spinal cord and compression of cervical spinal cord by posterior dislocation of $\mathrm{C} 2$ vertebral body. After 5 days of skull traction with $5 \mathrm{~kg}$ weight before operation, the dislocation aggravated. A C2-3 anterior cervical discectomy and fusion (ACDF) was performed. At 6 months after operation, bony fusion was achieved, and MRI showed the T2-weighted signal hyperintensity of cervical spinal cord before surgery disappeared.

Conclusion: We proposed a new subtype of hangman's fractures here, type Ilb hangman's fractures: type II hangman's fracture with $\mathrm{C} 2$ posterior dislocation. C2-C3 ACDF is recommended for type llb hangman's fractures. Traction before surgery is not recommended.

\section{Introduction}

Hangman's fracture, also known as "traumatic spondylolisthesis of the axis (TSA)", is defined as bilateral fracture of the pars interarticularis of the $\mathrm{C} 2$ vertebra that causes traumatic spondylolisthesis of $\mathrm{C} 2[1]$. Hangman's fracture accounts for about $5 \%$ of all cervical spine fractures and $20 \%$ of all axis fractures[2]. The overwhelming majority of hangman's fractures cause anterior dislocation of C2. Hangman's fracture with posterior dislocation of $\mathrm{C} 2$ is extremely rare, only one paediatric case was reported in 2018 to date[3]. The classification system of hangman's fractures developed by Effendi[4] in 1981 and later modified by Levine and Edwards[5] in 1985 is most widely accepted nowadays. The management guideline for hangman's fractures is mainly based on the Levine and Edwards modified Effendi classification system. Hangman's fracture with C2 posterior dislocation do not fit into any of the subtypes of Levine and Edwards modified Effendi classification system and the management of hangman's fractures with $\mathrm{C} 2$ posterior dislocation is different from $\mathrm{C} 2$ anterior dislocation. Given that there is no case of adult hangman's fracture with $\mathrm{C} 2$ posterior dislocation reported, scarcely any experiences of management of this situation can be learned. We reported the first adult cases of Hangman's fracture 
with posterior dislocation of $\mathrm{C} 2$ here, proposed a new subtype of hangman's fractures and discussed management technical notes for the new subtype to avoid pitfalls.

\section{Methods}

\section{Ethics Statement}

The institutional Ethics Review Board of Air Force medical center of PLA approved the study. Moreover, we obtained written informed consent for the publication of this case by the patient.

\section{Case description}

A 31-year-old man presented neck pain and decreased muscle strength of upper limbs after fell into a $50 \mathrm{~cm}$ deep roadside ditch when riding a motorcycle was admitted in our institution on $29^{\text {th }}$ June 2016. The pain localized in the back side of neck, visual analogue scale (VAS) of neck pain is 8 , without radiating pain.

Physical examination revealed muscle strength of the bilateral upper extremities was grade 4 and slight numbness of bilateral upper extremities, no dysmyotonia or sphincter dysfunction were revealed. Laboratory tests revealed nothing abnormal. Neck Disability Index (NDI) of the patient before surgery was 0.88 , Frankel scale of the patient before surgery was $D$, and Japanese Orthopaedic Association (JOA) score[6] of the patient before surgery was 16 .

Radiograph and computed tomography (CT) on admission showed fractures through both pars of $\mathrm{C} 2$ and $\mathrm{C} 2$ posterior dislocation. The injury pattern did not fit any of the classic patterns based on Levine

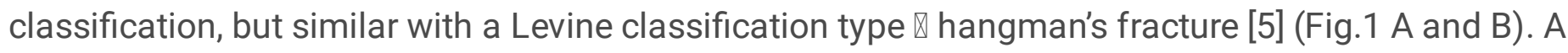
teardrop fracture of anterior-inferior side of C2 vertebral body is observed (Fig.1 A and B, arrowhead). Magnetic resonance imaging (MRI) on admission showed high T2-weighted signal intensity of cervical spinal cord and compression of cervical spinal cord by posterior dislocation of $\mathrm{C} 2$ vertebral body and ruptured C2-C3 intervertebral disc (Fig.1 C and D). After 5 days of skull traction through a Gardner-Wells tongue with $5 \mathrm{~kg}$ weight before operation, the dislocation aggravated (Fig.1 E).

A C2-3 anterior cervical discectomy and fusion (ACDF) was performed using a standard anterior SmithRobinson approach. After general anesthesia, the patient was placed in supine position. A $5 \mathrm{~cm}$ long incision standard anterior horizontal incision, about $1 \mathrm{~cm}$ below the right mandible, parallel to the mandible was made along the inner edge of sternocleidomastoid muscle toward the thyroid cartilage. The tissue was separated layer by layer to the front of cervical 2-3 intervertebral disc, the submandibular gland and supralaryngeal nerve were carefully protected. After confirming that the operation segment is correct by $\mathrm{C}$-arm, posterior dislocation of $\mathrm{C} 2$ vertebral body was found to be severe, and the reduction was difficult (Fig 2 A). The teardrop fracture fragment was removed, the C2-3 disc was removed completely, and the bone graft bed was fully prepared. A screw tap for limbs fracture (diameter: $4.5 \mathrm{~mm}$ ) was 
employed to drill into $\mathrm{C} 2$ vertebral body for traction and reduction under close nerve monitoring (Note that the position for titanium plate on C2 is reserved. Fig 2 B). A hook-shaped nerve dissector (Fig 2 C) was employed to hook the posterior-inferior edge of $\mathrm{C} 2$ vertebral body and pull anteriorly during the traction and reduction process to avoid $\mathrm{C} 2$ vertebral body sudden rebound and damage the cervical spinal cord. After reduction, the autogenous bone grafts harvested from the anterior inferior edge of $\mathrm{C} 2$ vertebral body and the posterior superior edge of $\mathrm{C} 3$ vertebral body were filled into a cage and implanted into C2-3 intervertebral space. The teardrop fracture fragment was put back to its original place (Fig $2 \mathrm{E}$, arrow). A titanium plate and 4 screws were used for internal fixation. Fracture reduction and fixation were confirmed by intraoperative C-arm imaging before closing the wound (Fig $2 \mathrm{D}$ and $\mathrm{E}$ ). Closure of the wound was performed in layers with the use of a wound drain which was removed after 24 hours. Postoperative cervical immobilization was accomplished by a Philadelphia collar for 12 weeks after operation.

\section{Results}

VAS of neck pain reduced to 2 immediately after operation and reduce to 0 at two weeks after operation. The patient was allowed to move freely with a Philadelphia collar one day after operation. At one week after operation, radiograph showed that internal fixation was good, and the reduction was satisfactory (Fig. 3A and B). At 6 months after operation, CT (Fig. 3C and D) and dynamic radiograph (Fig. 3E and F) showed bony fusion of C2-3 and both pars was achieved. MRI showed the T2-weighted signal hyperintensity of cervical spinal cord before surgery disappeared (Fig. 3G). NDI of the patient at 6 months after operation was 0.022 , Frankel scale of the patient at 6 months after operation was E, and JOA score of the patient at 6 months after operation was 17.

\section{Discussion}

Haughton firstly described bilateral fractures and dislocation of the axis pars interarticularis in human subjects executed by hanging in 1866[7]. Wood-Jones reported the bony anatomy of individuals executed by hanging with the knot in the submental position in 1913[8]. Schneider used the term "hangman's fracture" to describe this fracture pattern caused by traffic accidents in 1965[9]. Different from its original injury mechanism resulted from a submental knot position causing a hyperextension distraction injury, modern hangman's fracture is mainly resulted from falls and traffic accidents causing a hyperextension and compression injury[10]. Based on mechanism of injury and morphology of fracture, several classification systems for hangman's fracture have been proposed. The classification system developed by Effendi[4] and later modified by Levine and Edwards[5] is most widely accepted. According to their classification system, type I fractures are described as non-angulated and displacement $<3 \mathrm{~mm}$ result from a hyperextension-axial loading force; type $\otimes$ fractures are described as significant angulation $(>11$ degrees) and displacement (>3 $\mathrm{mm}$ ) result from a combined hyperextension-axial loading force, with an

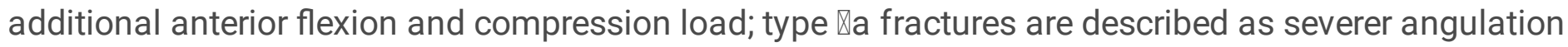
with minimal displacement result from a flexion-distraction force; type $₫$ fractures are described as severe 
angulation and displacement with facet dislocation result from a flexion-compression force. Our case did not fit into any of the four subtypes but bore close characteristics to type II fracture. Different from the typical C2 anterior displacement in most hangman's fractures which result in enlargement of spinal canal, posterior displacement of $\mathrm{C} 2$ in our patient resulted in compression of spinal cord and stenosis of spinal canal.

A teardrop fracture of $\mathrm{C} 2$ vertebral body is observed in the current case. Cervical tear drop fracture is divided into two types based on the mechanism of injury: flexion and extension. Extension teardrop fractures of $\mathrm{C} 2$ are caused by avulsion fracture of the bottom of the anteroinferior side of $\mathrm{C} 2$ vertebral body by anterior longitudinal ligament during hyperextension injury. Although tear drop fracture of $\mathrm{C} 2$ vertebral body usually manifest as a hyperextension injury[11, 12], the current case is more consistent with radiological features of a flexion teardrop fractures: backward displacement of the fractured body, posterior displacement of the upper column of the divided cervical spine, and kyphotic deformity of the cervical spine at the level of injury $[13,14]$. Different from the current case, extension teardrop fractures of C2 are usually described in elderly patients with osteoporosis and with no associated neurological deficit, for which surgery is rarely needed[11, 15]. Consistent with the current case, flexion teardrop fractures of C2 are usually described in younger patients with high-energy trauma and with high potential for cervical instability and neurological impairment, for which surgery is usually needed[14]. Considering the cause of injury, features of radiological finding and clinical symptoms of the patient, injury mechanism of the current case is speculated as a flexion-compression force.

To our knowledge, hangman's fracture with $\mathrm{C} 2$ posterior dislocation in adult is firstly reported here. Ibebuike et al reported an 8 years old male sustained a bilateral C2 pars fracture with C2 posterior subluxation on C3 case in 2018[3]. The paediatric case is similar to but different from our case. First, the paediatric case presented with significant angulation and minimal displacement, bore close characteristics to Levine and Edwards type $₫$ a fracture; while our case presented with significant angulation and sever displacement, bore close characteristics to Levine and Edwards type $\otimes$ fracture. Second, the paediatric case showed separation of the C2-C3 intervertebral disc from the C3 vertebrae through the cartilaginous layer without any disruption of the $\mathrm{C} 2-\mathrm{C} 3$ intervertebral disc and displaced C2C3 disc protruded into the intraspinal canal causing cord compression, while in our case the C2-C3 disc was ruptured and the cervical spinal cord was compressed by posterior dislocation of $\mathrm{C} 2$ vertebral body and ruptured C2-C3 intervertebral disc. Third, our case showed a tear-drop fracture while the paediatric case didn't. Forth, a flexion-distraction injury mechanism was inferred in the paediatric case while a flexion-compression injury mechanism was inferred in our case. These differences may be due to the differences in the anatomical structure of the spine between adults and children. The wedge shaped anteroinferior edge of paediatric developing $\mathrm{C} 2$ vertebral body is different from adult which may have facilitated the posterior slippage of $\mathrm{C} 2$ on $\mathrm{C} 3[16,17]$. Interestingly, the fracture of $\mathrm{C} 2$ anteroinferior edge in our case (teardrop morphology) also made the $\mathrm{C} 2$ vertebral body of the adult become a wedge-shaped anteroinferior edge like that of a paediatric $\mathrm{C} 2$ vertebral body. The combination between intervertebral disc and endplate in children is loose and intervertebral disc has not yet degenerated in children, this may have led to the C2-C3 disc was intact and totally prolapsed in the paediatric case. 
Concerning that this unique subtype of hangman fracture is rare but do exist and cannot be catalogued using current classification schemes, we suggest that this unique subtype of hangman fracture be defined as type Ilb: type II hangman's fracture with C2 posterior dislocation. Its injury mechanism is speculated as a flexion-compression force. The Levine and Edwards modified Effendi classification system of hangman's fractures was developed in 1980's while the first paediatric case of hangman's fracture with C2 posterior dislocation was reported in 2018 and the first adult case of hangman's fracture with C2 posterior dislocation was reported here. We can infer that the situation of C2 posterior dislocation was not taken into account when Effendi, Levine and Edwards proposed their classification system of hangman's fractures. C2 vertebral body is always anterior dislocation in other type of hangman's fractures which enlarges the spinal canal, so spinal cord injury is rare in hangman's fractures with an incidence of $6.5-10.3 \%[2,18,19]$. Different from other type of hangman's fractures, C2 vertebral body posterior displaced and C2-C3 intervertebral disc ruptured in type Ilb hangman's fractures, resulting in spinal canal stenosis and cord compression. Both reported cases showed symptoms of spinal cord injury (incidence: $100 \%$ ).

The guidelines for the management of hangman's fractures are mainly based on the Levine and Edwards classification nowadays. The fusion rate of non-operative treatment for hangman's fractures is $100 \%$ in

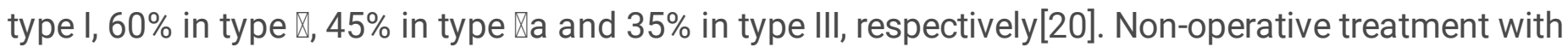
immobilization either with cervical collar or halo-vest is choice for stable hangman's fractures or for the patients with surgical contraindications[21-23]. Surgical stabilization techniques through anterior, posterior, and combined anteroposterior approaches have been reported for treating unstable hangman's fractures[1, 24-29]. Surgical options for unstable hangman's fractures through anterior approaches rely on a C2-C3 ACDF while posterior approaches mainly rely on a C2-C3 posterior cervical decompression and fusion (PCDF) with C2 pedicle and C3 lateral mass screws[1]. Both an anterior and a posterior approach result in a high rate of fusion [22], but C2-C3 ACDF seems to be superior to posterior approach as it is less invasive, simpler procedure, fewer complications, direct access to the main pathology and effectively restore cervical lordosis [21, 30-33].

C2-C3 ACDF is obviously more suitable for type Ilb hangman's fractures than posterior approach for the following reasons: First, instead of C2 anterior dislocation which results in widening the canal in most hangman's fractures, there is a posterior dislocation of C2 vertebral body and rupture of C2-C3 intervertebral disc in type Ilb hangman's fractures, which results in spinal canal stenosis and spinal cord compression. C2-C3 ACDF can directly decompression, reduction and effectively restore cervical lordosis. Second, concerning that bilateral pars of C2 was completely ruptured and displaced in type IIb hangman's fractures due to severe flexion-compression force, $\mathrm{C} 2$ pedicle screws are difficult to be implanted and the holding force of screws are poor. Third, there is cervical spinal canal stenosis and spinal cord compression in type Ilb hangman's fractures, spinal cord injury can be aggravated by positioning for posterior surgery. Forth, C2-C3 intervertebral discs are totally ruptured, bilateral pars of C2 are completely ruptured, and C2 bodies are severely displaced posteriorly in type Ilb hangman's fractures, the stability of anterior cervical column is so poor that posterior fixation alone may be difficult to maintain spinal stability. 
There are pitfalls in C2-C3 ACDF for type llb hangman's fractures. First, traction before surgery is not recommended for type llb hangman's fractures. Traction before surgery for cervical spine fracture is reported to be safe and effective for the reduction of acute traumatic spinal deformity in awake patients and approximately $80 \%$ of patients will have their cervical fracture dislocation injuries reduced with this technique[34, 35]. In the situation of type Ilb hangman's fractures, however, traction before surgery may aggravate $\mathrm{C} 2$ posterior dislocation, making reduction through $\mathrm{C} 2-\mathrm{C} 3 \mathrm{ACDF}$ more difficult and may aggravate spinal cord injury. Both reported type Ilb hangman's fracture cases showed dislocation aggravated after traction before surgery. Second, anterior exposure in C2-C3 region is considered to be difficult, Injury of submandibular gland and supralaryngeal nerve can happen during exposure. The risk of side injuries can be reduced by accumulation of surgical experiences by skilled surgeons. Third, reduction of C2 posterior dislocation can be very difficult during the surgery. In our experience, a screw tap for limbs fracture (diameter: $4.5 \mathrm{~mm}$ ) was employed to drill into $\mathrm{C} 2$ vertebral body for traction and reduction under close nerve monitoring. A larger diameter of a screw tap for limbs fracture guarantees a stronger holding force for traction and reduction. The entry point of screw tap should be located at least $0.8 \mathrm{~cm}$ above the anterior inferior edge of $\mathrm{C} 2$ vertebral body, so as to reserve room for plate in advance. A hook-shaped nerve dissector was employed to hook the posterior edge of C2 vertebral body and pull anteriorly during the traction and reduction process to avoid $\mathrm{C} 2$ vertebral body sudden rebound and damage the cervical spinal cord. Traction of screw tap should be maintained when implanting plate and cage to avoid loss of reduction and sudden rebound of $\mathrm{C} 2$ vertebral body. Forth, posterior longitudinal ligament resection is not necessary if there is no $\mathrm{C} 2-\mathrm{C} 3$ disc prolapse. Spinal canal is wide in the upper cervical region and spinal cord compression in type Ilb hangman's fractures is mainly caused by $\mathrm{C} 2$ posterior dislocation, spinal cord compression can be solved if the reduction and fusion is successful.

\section{Conclusion}

We proposed a new subtype of hangman's fracture here, type llb hangman's fractures: type II hangman's fracture with $\mathrm{C} 2$ posterior dislocation. C2-C3 ACDF is recommended for type llb hangman's fractures. Traction before surgery is not recommended.

\section{Abbreviations}

Traumatic Spondylolisthesis of the Axis: TSA

Visual Analogue Scale: VAS

Neck Disability Index: NDI

Japanese Orthopaedic Association: JOA

Computed Tomography: CT

Magnetic resonance imaging: MRI 


\section{Declarations}

\section{Ethics approval and consent to participate}

The institutional Ethics Review Board of Air Force medical center of PLA approved the study.

\section{Consent for publication}

Written informed consent for publication of the patient's clinical details and clinical images was obtained from the patient.

\section{Availability of data and materials}

All data generated or analysed during this study are included in this published article.

\section{Competing interests}

The authors declare that they have no competing interests.

\section{Funding}

This study was supported by PLA military logistics research foundation (No. BKJ20J004 and BKJ17J004)

\section{Authors' contributions}

All authors have read and approved the final submitted manuscript. All the authors were involved in conducting, drafting, and revising the manuscript. Study conception and supervision: Jun-Jie Du and YuFei Chen. Surgery: Jun-Jie Du and Shuang Ma. Case follow-up and literatures research: Guan-Nan Luan, Xiao-jie Li, Hong-Xing Zhang and Ye Peng. Review of literatures and interpretation of data: Guan-Nan Luan, Jing-Yuan Li, Song-Lin Li, Xiao-jie Li and Jing Xue.

\section{Acknowledgements}

Not applicable. 


\section{References}

1. Turtle J, Kantor A, Spina NT, France JC, Lawrence BD. Hangman's Fracture. Clin Spine Surg. 2020;33(9):345-54.

2. Greene KA, Dickman CA, Marciano FF, Drabier JB, Hadley MN, Sonntag VK. Acute axis fractures. Analysis of management and outcome in 340 consecutive cases. Spine (Phila Pa 1976). 1997;22(16):1843-52.

3. Ibebuike K, Roussot M, Watt J, Dunn R. Management challenges of traumatic spondylolisthesis of the Axis with an unusual C2-C3 posterior subluxation in a paediatric patient: case report and literature review. Afr Health Sci. 2018;18(2):458-67.

4. Effendi B, Roy D, Cornish B, Dussault RG, Laurin CA. Fractures of the ring of the axis. A classification based on the analysis of 131 cases. J Bone Joint Surg Br. 1981;63-B(3):319-27.

5. Levine AM, Edwards CC. The management of traumatic spondylolisthesis of the axis. J Bone Joint Surg Am. 1985;67(2):217-26.

6. Yonenobu K, Abumi K, Nagata K, Taketomi E, Ueyama K. Interobserver and intraobserver reliability of the japanese orthopaedic association scoring system for evaluation of cervical compression myelopathy. Spine (Phila Pa 1976). 2001;26(17):1890-4. discussion 1895.

7. S. H: On hanging, considered from a mechanical and physiological point of view. London, Edinburgh and Dublin Philosophical Magazine and Journal of Science 1866, 32(4):23-34.

8. F. W-J: The ideal lesion produced by judicial hanging. Lancet 1913, i:53.

9. Schneider RC, Livingston KE, Cave AJ, Hamilton G. "Hangman's Fracture" of the Cervical Spine. J Neurosurg. 1965;22:141-54.

10. Pryputniewicz DM, Hadley MN. Axis fractures. Neurosurgery. 2010;66(3 Suppl):68-82.

11. Kim HJ, Lee KY, Kim WC. Treatment outcome of cervical tear drop fracture. Asian Spine J. 2009;3(2):73-9.

12. Ianuzzi A, Zambrano I, Tataria J, Ameerally A, Agulnick M, Goodwin JS, Stephen M, Khalsa PS. Biomechanical evaluation of surgical constructs for stabilization of cervical teardrop fractures. Spine J. 2006;6(5):514-23.

13. Kim KS, Chen HH, Russell EJ, Rogers LF. Flexion teardrop fracture of the cervical spine: radiographic characteristics. AJR Am J Roentgenol. 1989;152(2):319-26.

14. Signoret F, Jacquot FP, Feron JM. Reducing the cervical flexion tear-drop fracture with a posterior approach and plating technique: an original method. Eur Spine J. 1999;8(2):110-6.

15. Watanabe M, Sakai D, Yamamoto Y, Sato M, Mochida J. Clinical features of the extension teardrop fracture of the axis: review of 13 cases. J Neurosurg Spine. 2011;14(6):710-4.

16. Kokoska ER, Keller MS, Rallo MC, Weber TR. Characteristics of pediatric cervical spine injuries. J Pediatr Surg. 2001;36(1):100-5. 
17. Duhem R, Tonnelle V, Vinchon M, Assaker R, Dhellemmes P. Unstable upper pediatric cervical spine injuries: report of 28 cases and review of the literature. Childs Nerv Syst. 2008;24(3):343-8.

18. Muller EJ, Wick M, Muhr G. Traumatic spondylolisthesis of the axis: treatment rationale based on the stability of the different fracture types. Eur Spine J. 2000;9(2):123-8.

19. Pepin JW, Hawkins RJ. Traumatic spondylolisthesis of the axis: Hangman's fracture. Clin Orthop Relat Res 1981(157):133-138.

20. Li XF, Dai LY, Lu H, Chen XD. A systematic review of the management of hangman's fractures. Eur Spine J. 2006;15(3):257-69.

21. Schleicher P, Scholz M, Pingel A, Kandziora F. Traumatic Spondylolisthesis of the Axis Vertebra in Adults. Global Spine J. 2015;5(4):346-58.

22. Murphy H, Schroeder GD, Shi WJ, Kepler CK, Kurd MF, Fleischman AN, Kandziora F, Chapman JR, Benneker LM, Vaccaro AR. Management of Hangman's Fractures: A Systematic Review. J Orthop Trauma. 2017;31(Suppl 4):90-5.

23. Prost S, Barrey C, Blondel B, Fuentes S, Barresi L, Nicot B, Challier V, Lleu M, Godard J, Kouyoumdjian $P$, et al. Hangman's fracture: Management strategy and healing rate in a prospective multi-centre observational study of 34 patients. Orthop Traumatol Surg Res. 2019;105(4):703-7.

24. Patel JYK, Kundnani VG, Kuriya S, Raut S, Meena M. Unstable Hangman's fracture: Anterior or posterior surgery? J Craniovertebr Junction Spine. 2019;10(4):210-5.

25. Singh PK, Agrawal M, Sawarkar D, Kumar A, Verma S, Doddamani R, Chandra PS, Kale SS.

\section{Management of neglected complex hangman's fracture by reforming the $\mathrm{C} 2$ pedicle: new innovative technique of motion preservation at the C1-2 joint in 2 cases. J Neurosurg Spine 2020:1-8.}

26. Soliman MAR, Kwan BYM, Jhawar BS. Minimally Invasive Unilateral Percutaneous Transfracture Fixation of a Hangman's Fracture Using Neuronavigation and Intraoperative Fluoroscopy. World Neurosurg. 2019;122:90-5.

27. Li G, Wang Q, Liu H, Hong Y. Individual Surgical Strategy Using Posterior Lag Screw-Rod Technique for Unstable Atypical Hangman's Fracture Based on Different Fracture Patterns. World Neurosurg. 2018;119:e848-54.

28. Jain V, Thakur MK, Thakur A, Sud S, Lal M, Madan A. Functional outcome in unstable Hangman's fracture managed with anterior approach: A prospective study. J Craniovertebr Junction Spine. 2017;8(4):350-3.

29. Wang J, Chen H, Cao P, Yuan W, Wu X, Liu G, Li R, Zang F, Shi L, Wang A. Combined Anterior-Posterior Fixation and Fusion for Completely Dislocated Hangman's Fracture: A Retrospective Analysis of 11 Cases. Clin Spine Surg. 2017;30(8):E1050-4.

30. Ge C, Hao D, He B, Mi B. Anterior cervical discectomy and fusion versus posterior fixation and fusion of C2-3 for unstable hangman's fracture. J Spinal Disord Tech. 2015;28(2):E61-6.

31. Wei F, Pan X, Zhou Z, Cui S, Zhong R, Wang L, Gao M, Chen N, Liang Z, Zou X, et al. Anterior-only stabilization using cage versus plating with bone autograft for the treatment of type II/IIA Hangman's fracture combined with intervertebral disc injury. J Orthop Surg Res. 2015;10:33. 
32. Wei F, Wang L, Zhou Z, Zhong R, Liu S, Cui S, Pan X, Gao M. Cervical cage without plating in management of type II / II A Hangman's fracture combined with intervertebral disc injury. BMC Musculoskelet Disord. 2015;16:285.

33. Li Z, Li F, Hou S, Zhao Y, Mao N, Hou T, Tang J. Anterior discectomy/corpectomy and fusion with internal fixation for the treatment of unstable hangman's fractures: a retrospective study of 38 cases. J Neurosurg Spine. 2015;22(4):387-93.

34. Gelb DE, Hadley MN, Aarabi B, Dhall SS, Hurlbert RJ, Rozzelle CJ, Ryken TC, Theodore N, Walters BC. Initial closed reduction of cervical spinal fracture-dislocation injuries. Neurosurgery. 2013;72(Suppl 2):73-83.

35. Aebi M. Surgical treatment of upper, middle and lower cervical injuries and non-unions by anterior procedures. Eur Spine J. 2010;19(Suppl 1):33-9.

\section{Figures}
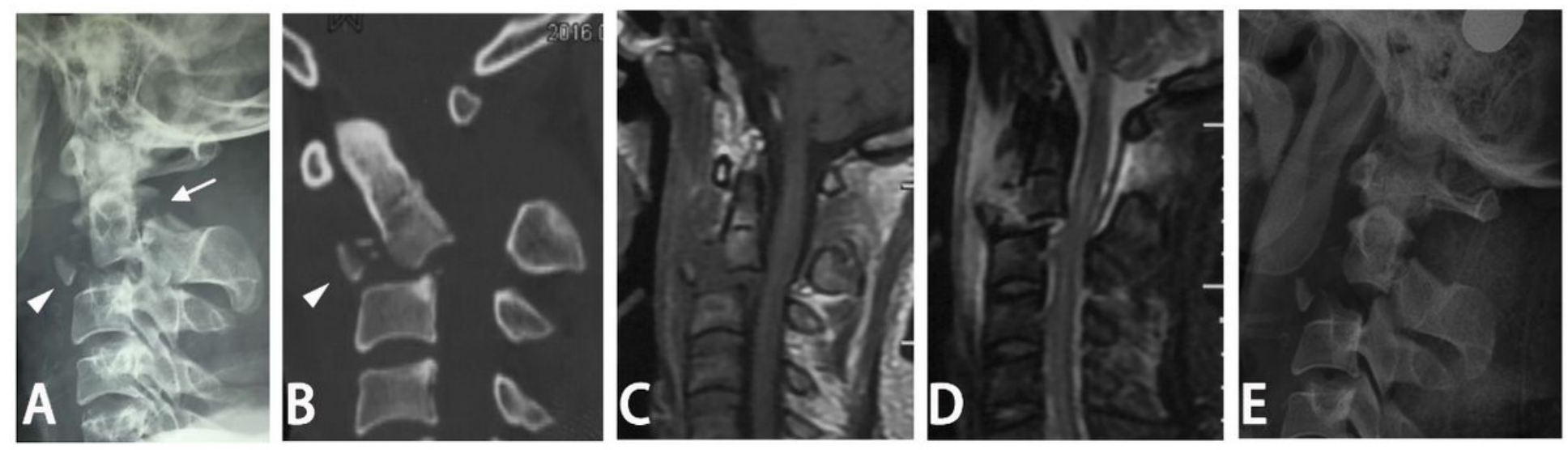

Figure 1

Radiological imaging before surgery A) Lateral cervical spine radiograph showed fractures through both pars of C2 (arrow) and C2 posterior dislocation. A teardrop fracture of anterior-inferior side of C2 vertebral body is observed (arrowhead). B) Computed tomography showed C2 posterior dislocation and angulation is severe. A teardrop fracture of anterior-inferior side of C2 vertebral body is observed (arrowhead). C) and D) Magnetic resonance imaging showed that spinal cord was compressed anteriorly by posterior dislocation of C2 vertebral body and ruptured C2-C3 intervertebral disc and T2-weighted signal hyperintensity of cervical spinal cord. E) After 5 days of skull traction with $5 \mathrm{~kg}$ weight before operation, the dislocation aggravated. 

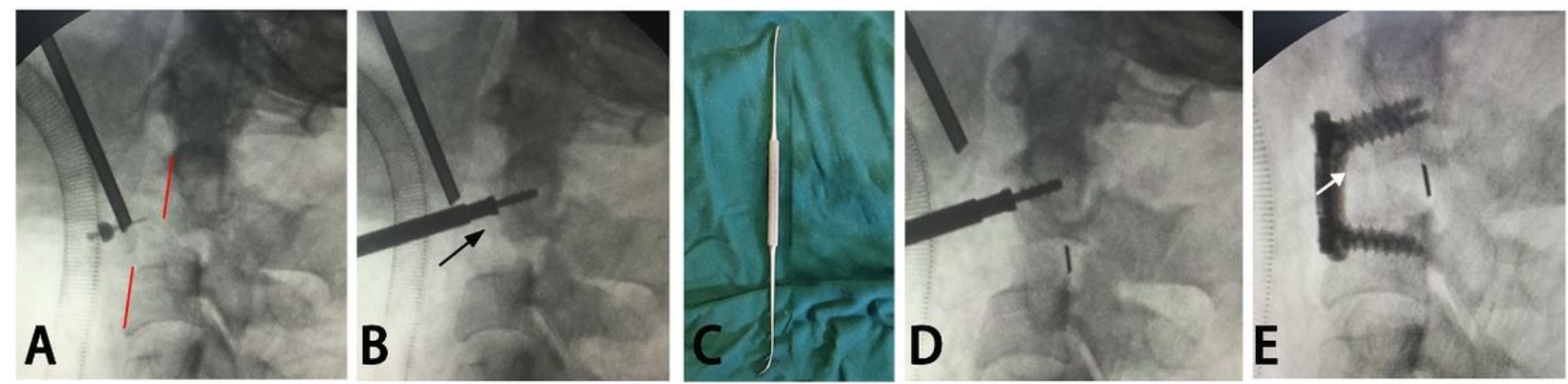

\section{Figure 2}

Radiological imaging during surgery A) Lateral cervical spine radiograph by intraoperative $\mathrm{C}$-arm showed posterior dislocation of $\mathrm{C} 2$ vertebral body severe, and the reduction was difficult. B) A screw tap for limbs fracture was employed to drill into $\mathrm{C} 2$ vertebral body for traction and reduction under close nerve monitoring. Arrow: the position for titanium plate on $\mathrm{C} 2$ is reserved. C) A hook-shaped nerve dissector was employed to hook the posterior edge of cervical 2 vertebral body during the traction and reduction process to avoid $\mathrm{C} 2$ vertebral body sudden rebound and damage the cervical spinal cord. D) and E) Fracture reduction and fixation were confirmed by intraoperative $\mathrm{C}$-arm imaging before closing the wound. The teardrop fracture fragment was put back to its original place (arrow).
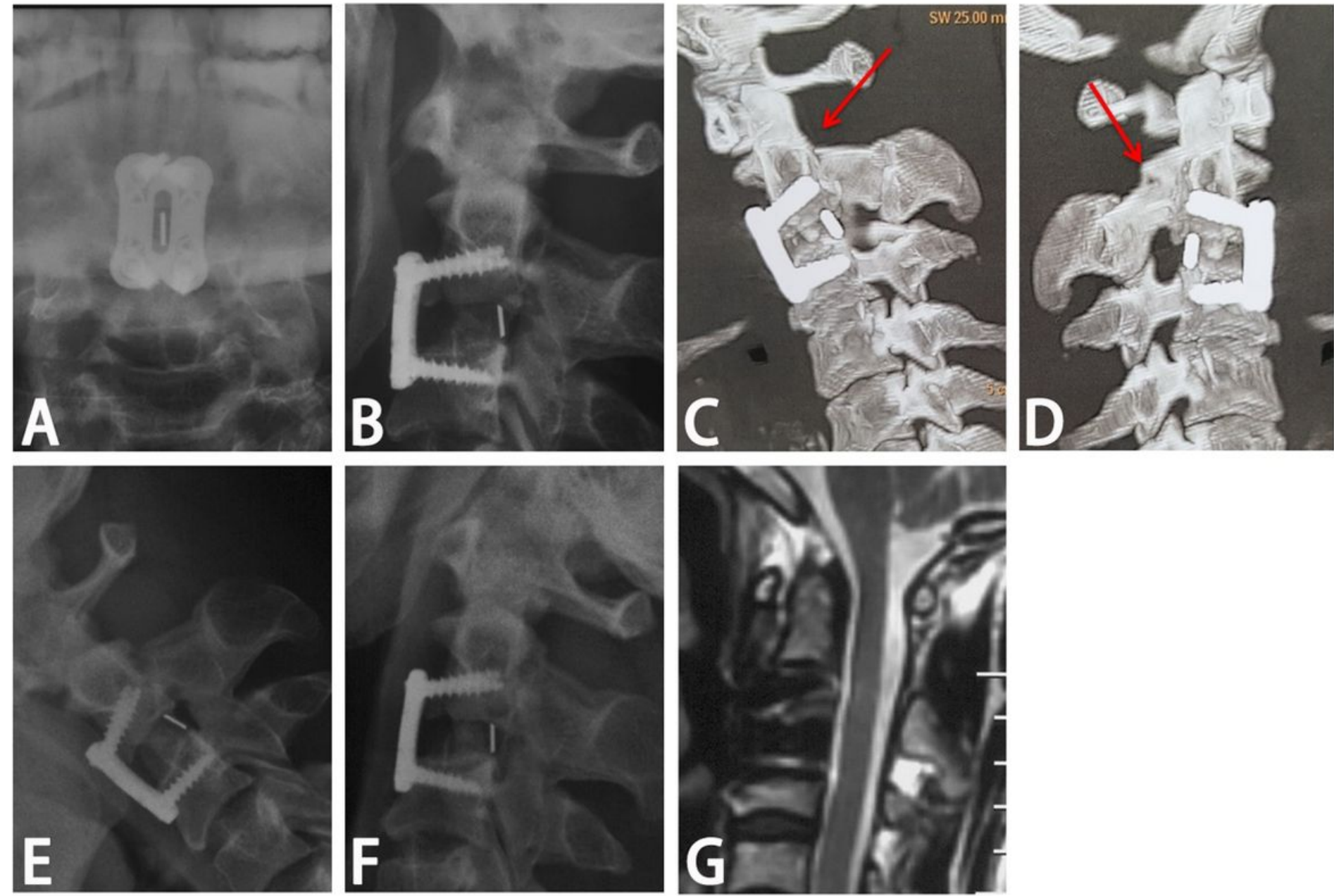


\section{Figure 3}

Radiological imaging at follow-ups A) and B) Cervical spine radiograph at one week after operation showed that internal fixation was good, and the reduction was satisfactory. C) and D) Computed tomography at 6 months after operation showed bony fusion of C2-3 and both pars was achieved. Arrow: bony fusion of left (C) and right (D) pars was achieved. E) and F) Cervical spine dynamic radiograph at 6 months after operation showed cervical stability was good. G) Magnetic resonance imaging at 6 months after operation showed the T2-weighted signal hyperintensity of cervical spinal cord before surgery disappeared. 